\title{
Catastrophic health expenditure due to hospitalisation for COVID-19 treatment in India: findings from a primary survey
}

\author{
Samir Garg ${ }^{*}$ (D, Kirtti Kumar Bebarta, Narayan Tripathi and C. Krishnendhu
}

\begin{abstract}
Objective: The COVID-19 pandemic has caused widespread illness and a significant proportion of the infected required hospitalisation for treatment. People in developing countries like India were vulnerable to high hospitalisation costs. Despite its crucial importance, few primary studies are available on this aspect of the pandemic. This study was aimed at finding out the out of pocket expenditure (OOPE) and incidence of catastrophic expenditure on hospitalisation of persons infected with COVID-19. A primary survey of 492 randomly selected hospitalisations of individuals tested positive for COVID-19 in high-burden districts during August to November 2020 was carried out telephonically in Chhattisgarh state of India.

Results: Public hospitals accounted for $69 \%$ of the hospitalisations for COVID-19 treatment. Mean OOPE per hospitalisation was Indian Rupees (INR) 4871 in public hospitals and INR 169,504 in private hospitals. Around 3\% of hospitalisations in public hospitals and 59\% in private hospitals resulted in catastrophic expenditure, at a threshold of $40 \%$ of non-food annual household expenditure. Enrolment under publicly or privately funded health insurance was not effective in curtailing OOPE. Multivariate analysis showed that utilisation of private hospitals was a key determinant of incurring catastrophic expenditure.
\end{abstract}

Keywords: Hospitalisation, Expenditure, Out of pocket, Catastrophic expenditure, Financial protection, COVID-19, Private sector, India, Insurance

\section{Introduction}

The COVID-19 pandemic has affected countries across the world and has caused widespread illness, mortality and economic catastrophe [1-3]. Globally, a large number of individuals infected with COVID-19 had to be admitted in hospitals for treatment [4]. Researchers have expressed a concern that a large number of households in developing countries including India were vulnerable to catastrophic expenditure for COVID-19 related hospitalisations due to the existing dependence of health systems on Out of Pocket Expenditure (OOPE) [5-8]. India was among the worst affected countries in the world in

*Correspondence: koriya@gmail.com

State Health Resource Centre, Raipur, Chhattisgarh, India terms of the number of COVID-19 infected persons [4]. The health system in India is a mixed one with a substantial presence of for-profit private sector alongside public facilities [9]. OOPE constitutes around $60 \%$ of the Total Health Expenditure in Indian health system [10]. In such a situation, it is of crucial importance to know the financial burden borne by the households on hospitalisation for COVID-19 treatment.

In terms of policy responses in India, the central and state governments tried to expand the capacity of public hospitals and offered free services for COVID-19 treatment [11]. India has a Publicly Funded Health Insurance (PFHI) programme known as Ayushman Bharat-Pradhan Mantri Jan Arogaya Yojana (PMJAY) to cover inpatient care costs in public as well as private hospitals 
$[11,12]$. In addition, governments in many states of India declared price ceilings for COVID-19 related care in private hospitals [13-19]. However, not much is known regarding the effectiveness of above measures.

The current study was aimed at finding out the OOPE and incidence of catastrophic health expenditure (CHE) for hospitalisations of COVID-19 cases.

\section{Main text \\ Materials and methods \\ Study setting}

The study was conducted in the Indian state of Chhattisgarh. It is one of the poorest states in India and has a population of around 29 million [20]. From August 2020 onwards, government allowed private hospitals in the state to admit COVID-19 cases [21]. Home Isolation was allowed for COVID-19 positive cases with mild or no symptoms [22]. The state had universal enrolment under its PFHI schemes that included PMJAY [23, 24]. Starting from April 2020, PMJAY had allowed the states to include testing and hospitalisation for COVID-19 under its cover [12]. Following the above decision, the state invited private hospitals to get empanelled to provide hospitalisation care for COVID-19 cases at the following prices per day: Indian Rupees (INR) 2200 for care in general ward, INR 3750 for care in Intensive Care Unit (ICU) and INR 6750 for ICU with ventilation support [25]. However, none of the private hospitals came forward to get empanelled for COVID-19 care under the above scheme [23].

In August 2020, the state government declared a ceiling on prices that the private hospitals could charge from COVID-19 patients. The per-day ceiling was INR 6200 for care at general ward with oxygen support, INR 12,000 for care at ICU, INR 17,000 for ventilator support [13].

Study design and sampling: The study was based on a cross-sectional survey of COVID-19 cases. The survey was done in December, 2020 by the State Health Resource Centre, a technical agency working for the state's department of health. A structured quantitative questionnaire was used. Due to poor feasibility of conducting in-person interviews during the pandemic, the survey was carried out telephonically. The survey and its quality-assurance were informed by the guidance available for conducting phone-based surveys in developing countries during the COVID-19 pandemic [26-29]. In case of participants below 18 years age, either of the parents was interviewed.

The sample consisted of COVID-19 positive individuals who got hospitalised for its treatment. COVID-19 positive was taken as those confirmed for COVID-19 using diagnostics approved by Indian government. Government rules made it mandatory for all providers to record all tests done for COVID-19 on a centralized online database. A list of 181,616 confirmed cases of COVID-19 in
Chhattisgarh during the study period (August to November 2020) was obtained from the government. The top three districts in the state in terms of most number of cases were selected for survey. The minimum sample size required at $95 \%$ confidence was calculated as 385 hospitalisations. Expecting one-third of the COVID-19 cases to be hospitalised, a sample of three times i.e. 1155 cases was needed. In order to allow for a refusal rate of $50 \%$ in the telephonic survey, 2310 cases were taken using systematic random selection. The survey was able to complete interviews of 1294 individuals out of the above list. The above interviews yielded 492 participants who had been hospitalised for COVID-19 treatment and they formed the sample for this study.

OOPE for hospitalisation was taken as all medical expenses paid in cash by the patient/family including all charges paid to hospital and any medicines bought. The expenditure on transportation for hospitalisation was asked separately. The expenditure on testing for COVID19 before hospitalisation was also asked separately. There were no cash-reimbursements received by the patients.

Financial Protection was measured in terms of catastrophic health expenditure (CHE) as proposed by Wagstaff and Doorslaer [30]. The survey collected data on monthly consumption expenditure on food and non-food purposes. The incidence of CHE was calculated using a threshold based on a proportion of annual non-food consumption expenditure. A threshold of $40 \%$ of concerned household's annual non-food consumption expenditure was taken and named CHE40.This is a commonly used measure of CHE [30].

The list of study variables is given in Additional file 1: Table S1.

Confidence Intervals (CI) were computed for mean at 95\% and reported in parentheses. Multi-variate logistic regression was used to find out determinants of CHE40. As recommended in existing studies, quantile regression was applied for OOPE as it offers advantages in addressing any skew or extreme values in the OOPE data [31]. For comparison, linear regression was also applied for OOPE. All analyses were carried out using STATA 15.

\section{Ethical considerations}

The ethics approval for the study was obtained from the Institutional Ethics Committee of the State Health Resource Centre, Chhattisgarh [Reference No. SHRC-042020]. The consent form was read out to each participant. The interview was started only when an explicit consent was provided by participants. A log was maintained for every call-name of caller, date and time, note that the prescribed text was used for asking consent, record of participant's response and signature of caller. In order to ensure confidentiality and quality, an in-house call-centre 
was used. The calls were supervised closely to ensure adherence to the protocol. The log of each caller was examined and signed daily by the concerned supervisor. The dataset was completely anonymised.

\section{Results}

Of the COVID-19 positive individuals interviewed, $83.1 \%$ (80.9-85.1\%) had been tested for COVID-19 by government providers. Among the COVID-19 positive individuals interviewed, 38\% (35.440.7\%) had got hospitalised.

The socio-demographic characteristics of the hospitalised COVID-19 positive individuals are given in Table 1.

The mean annual household expenditure of the hospitalised participants was INR 339,643 (273,607-405,679) and its median value was INR 267,000.

Around $12 \%$ of the hospitalised individuals were enrolled under private health insurance. Private health

Table 1 Socio-demographic characteristics of individuals interviewed and individuals hospitalised among them

\begin{tabular}{lc}
\hline Characteristics and categories & $\begin{array}{c}\text { Hospitalised } \\
\text { individuals } \\
\mathbf{N}=\mathbf{4 9 2} \%)\end{array}$ \\
\hline Place of residence & \\
$\quad$ Rural & $134(27.24)$ \\
Urban & $358(72.76)$ \\
Age (years) & \\
0-14 & $15(3.08)$ \\
15-39 & $231(47.43)$ \\
40-59 & $163(33.47)$ \\
Above 60 & $78(16.02)$ \\
Sex & \\
Male & $342(69.51)$ \\
Female & $150(30.49)$ \\
Education & \\
Not literate & $24(4.79)$ \\
Primary & $62(12.50)$ \\
High school & $87(17.71)$ \\
12th standard & $99(20.21)$ \\
Graduation and above & $220(44.79)$ \\
Per-capita household expenditure quintile & \\
Quintile 1 (poorest) & \\
Quintile 2 & $119(25.93)$ \\
Quintile 3 & $73(15.90)$ \\
Quintile 4 & $95(20.70)$ \\
Quintile 5 & $81(17.65)$ \\
Up to 5 members & $91(19.83)$ \\
Above 5 members & \\
Enrolled & $188(38.21)$ \\
\hline & \\
\hline
\end{tabular}

insurance in Indian context refers to voluntary insurance bought by individuals from private insurers to cover costs of utilizing private hospitals [32].

Among those who got hospitalised, 69.3\% (65.1-73.4\%) were hospitalised in public facilities and the rest utilised for-profit private hospitals. Among hospitalisations, $15.6 \%$ were shorter than a week, $68.8 \%$ were 7 to 13 days long and $15.5 \%$ were 2 weeks or longer. The mean duration of hospitalisation was around 10 days for both public and private hospitals. Of the hospitalised, $7.5 \%$ utilised ventilator support, $10.8 \%$ used oxygen (without ventilator) and $16.5 \%$ received anti-viral injections.

The mean expenditure incurred by patients for testing for COVID-19 was INR 130 (62-197) for public hospitals and INR 2003 (1359-2647) for private hospitals. The mean expenditure incurred by patients for transportation for hospitalisation was INR 280 (135-424) for public hospitals and INR 791 (360-1222) for private hospitals.

The mean OOPE on hospitalisation was INR 169,504 $(142,094-196,914)$ in private hospitals and INR 4871 (3068-6674) in public hospitals. Among the hospitalisations in private hospitals, $87.1 \%(80.2-94.1 \%)$ involved charges exceeding the price caps declared by government.

The quantile regression for OOPE showed that utilising private hospitals involved significantly greater OOPE than public hospitals (Table 2). Receiving ventilator support or anti-viral injections involved greater OOPE. Enrolment under the private health insurance did not have a significant association with OOPE. The linear regression model showed a similar pattern (Additional file 2: Table S2).

Among those hospitalised in public hospitals, 3.2\% (1.8-5.7\%) incurred CHE40. Among those hospitalised in private hospitals, 58.9\% (50.5-66.74\%) incurred CHE40. Overall, 20.3\% (16.9-24.1\%) of the hospitalised incurred CHE40. Using private hospitals involved significantly greater likelihood of catastrophic expenditure than those using public hospitals (Table 3). Enrolment in private health insurance did not have a significant association with CHE40.

\section{Discussion}

The study period of August to November 2020 corresponded to the first wave of surge in COVID-19 infections in India [33]. Those admitted in private hospitals incurred thirty-five times larger OOPE than the admissions in public hospitals. The adjusted model showed that hospitalisation in private facilities was far more likely to cause catastrophic expenditure than the public facilities. This confirms the apprehensions regarding the possibility of catastrophic expenditure due to COVID-19, especially for hospitalisations in the private sector $[6,34,35]$. 
Table 2 Quantile regression for size of OOPE on COVID-19 hospitalisation

\begin{tabular}{|c|c|c|c|c|c|c|}
\hline & OOPE & Coef & SE & $P$ value & $95 \% \mathrm{Cl}$ & \\
\hline \multirow[t]{2}{*}{ Residence } & Rural & 1 & & & & \\
\hline & Urban & 0 & 6327 & 1 & $-12,541$ & 12,541 \\
\hline \multirow[t]{4}{*}{ Age } & $0-14$ years & 1 & & & & \\
\hline & $15-39$ years & 0 & 16,819 & 1 & $-33,320$ & 33,320 \\
\hline & $40-59$ years & 0 & 16,607 & 1 & $-32,820$ & 32,820 \\
\hline & Above 60 & 0 & 17,330 & 1 & $-34,207$ & 34,207 \\
\hline \multirow[t]{2}{*}{ Sex } & Male & 1 & & & & \\
\hline & Female & 0 & 5906 & 1 & $-11,612$ & 11,612 \\
\hline \multirow[t]{5}{*}{ Education } & Not literate & 1 & & & & \\
\hline & Primary & 0 & 9617 & 1 & $-18,907$ & 18,907 \\
\hline & High school & 0 & 10,129 & 1 & $-19,914$ & 19,914 \\
\hline & 12th standard & 0 & 10,489 & 1 & $-20,621$ & 20,621 \\
\hline & Graduation and above & 0 & 14,725 & 1 & $-28,950$ & 28,950 \\
\hline \multirow[t]{2}{*}{ Household size } & Up to 5 members & 1 & & & & \\
\hline & Above 5 members & 0 & 5925 & 1 & $-11,648$ & 11,648 \\
\hline \multirow{5}{*}{$\begin{array}{l}\text { Per capita household expenditure } \\
\text { quintile }\end{array}$} & Poorest & 1 & & & & \\
\hline & Poor & 0 & 8744 & 1 & $-17,191$ & 17,191 \\
\hline & Middle & 0 & 8412 & 1 & $-16,538$ & 16,538 \\
\hline & Rich & 0 & 8974 & 1 & $-17,644$ & 17,644 \\
\hline & Richest & 1000 & 9320 & 0.91 & $-17,323$ & 19,323 \\
\hline \multirow[t]{2}{*}{ Type of hospital } & Public & 1 & & & & \\
\hline & Private & 133,000 & 6720 & $<0.01$ & 119,787 & 146,213 \\
\hline Duration of hospitalisation & & 0 & 613 & 1.1 & -1206 & 1206 \\
\hline Ventilator & Used & 19,000 & 12,060 & 0.11 & -4710 & 42,710 \\
\hline Anti-viral injection & Used & 40,000 & 8767 & $<0.01$ & 22,763 & 57,237 \\
\hline Oxygen (without ventilator) & Used & 5000 & 9347 & 0.5 & $-13,376$ & 23,376 \\
\hline Private insurance & Insured & -2000 & 8888 & 0.8 & $-19,473$ & 15,473 \\
\hline
\end{tabular}

No. of observations: 413 ; pseudo R2: 0.37

The current study found that private insurance was ineffective in reducing the OOPE significantly. A recent study has examined the claims data of private insurance in India and expressed similar doubts regarding its effectiveness [36]. PFHI schemes in Indian context, including the national flagship programme PMJAY, have been found to be largely ineffective in reducing OOPE or CHE for inpatient care [20, 37-39]. The current study found that the PMJAY scheme could not cover COVID-19 care in private hospitals in Chhattisgarh in 2020.

In addition to existing laws on regulation of private hospitals, government enjoyed further powers under the epidemic related law invoked for COVID-19 [3]. The price ceilings announced by Chhattisgarh state were around three times greater than the prices it offered under PFHI. Yet, the private hospitals continued to charge above the price caps. According to grey literature, the price controls introduced by other states in India for COVID-19 hospitalisations were also quite ineffective [35]. This reflects the long-standing difficulties in achieving price regulation in private hospitals in India [32, 40-43].

A study from Peru has reported high OOPE for COVID-19 hospitalisations and ineffectiveness of health insurance [44]. Studies from USA have found significant OOPE for COVID-19 hospitalisations among the insured $[45,46]$. Examples of price gouging by private hospitals for COVID-19 care have been found in many countries in Africa [47]. In many health systems, the providers are known to wield a lot more power compared to the patients $[41,48]$. This power asymmetry seems to have worsened during the pandemic when widespread panic prevailed.

Some have advocated that governments should purchase care for COVID-19 from private sector hospitals [49-53]. The current study suggests that such strategies are unlikely to succeed in Indian context. Publicly provided care was found to be effective in ensuring financial protection. However, as public hospitals diverted a significant amount of their capacity to COVID-19 care, the 
Table 3 Logistic regression for CHE40 on COVID-19 hospitalisation

\begin{tabular}{|c|c|c|c|c|c|}
\hline & Odds ratio & SE & $p$ value & $95 \% \mathrm{C}$ & \\
\hline \multicolumn{6}{|l|}{ Residence } \\
\hline Rural & 1 & & & & \\
\hline Urban & 1.48 & 0.76 & 0.44 & 0.54 & 4.07 \\
\hline \multicolumn{6}{|l|}{ Age (years) } \\
\hline $0-14$ & 1 & & & & \\
\hline $15-39$ & 1.13 & 2.01 & 0.95 & 0.03 & 37.20 \\
\hline $40-59$ & 0.90 & 1.58 & 0.95 & 0.03 & 28.36 \\
\hline Above 60 & 1.30 & 2.31 & 0.88 & 0.04 & 42.06 \\
\hline \multicolumn{6}{|l|}{ Sex } \\
\hline Male & 1 & & & & \\
\hline Female & 3.09 & 1.36 & 0.01 & 1.31 & 7.30 \\
\hline \multicolumn{6}{|l|}{ Education } \\
\hline Not literate & 1 & & & & \\
\hline Primary & 0.79 & 0.53 & 0.72 & 0.21 & 2.93 \\
\hline High school & 0.65 & 0.47 & 0.55 & 0.16 & 2.70 \\
\hline 12th standard & 0.83 & 0.62 & 0.81 & 0.19 & 3.58 \\
\hline Graduation and above & 0.21 & 0.34 & 0.33 & 0.01 & 4.96 \\
\hline \multicolumn{6}{|l|}{ Household size } \\
\hline Up to 5 members & 1 & & & & \\
\hline Above 5 members & 0.44 & 0.18 & 0.05 & 0.19 & 1.00 \\
\hline \multicolumn{6}{|c|}{ Per capita household expenditure quintile } \\
\hline Poorest & 1 & & & & \\
\hline Poor & 0.54 & 0.39 & 0.39 & 0.13 & 2.20 \\
\hline Middle & 0.60 & 0.40 & 0.45 & 0.16 & 2.22 \\
\hline Rich & 0.95 & 0.61 & 0.93 & 0.27 & 3.36 \\
\hline Richest & 0.36 & 0.25 & 0.14 & 0.10 & 1.38 \\
\hline \multicolumn{6}{|l|}{ Type of hospital } \\
\hline Public & 1 & & & & \\
\hline Private & 59.77 & 30.47 & 0.01 & 22.00 & 162.34 \\
\hline $\begin{array}{l}\text { Duration of hospitali- } \\
\text { sation }\end{array}$ & 1.06 & 0.04 & 0.14 & 0.98 & 1.15 \\
\hline \multicolumn{6}{|l|}{ Ventilator } \\
\hline Used & 3.74 & 2.52 & 0.04 & 1.00 & 14.01 \\
\hline \multicolumn{6}{|l|}{ Anti-viral injection } \\
\hline Used & 2.34 & 1.05 & 0.06 & 0.97 & 5.64 \\
\hline \multicolumn{6}{|l|}{ Oxygen (without ventilator) } \\
\hline Used & 2.26 & 1.09 & 0.09 & 0.88 & 5.82 \\
\hline \multicolumn{6}{|l|}{ Private insurance } \\
\hline Insured & 0.67 & 0.31 & 0.39 & 0.27 & 1.68 \\
\hline
\end{tabular}

No. of observations: 413; pseudo R2: 0.5

availability of care for other ailments might have suffered [54].

For curtailing OOPE, the current study suggests the need for better regulation of charging in private hospitals. There is a need to strengthen capacity of public sector to manage a surge of hospitalisations during emergencies while maintaining other essential services.

\section{Limitations}

The usual limitations of cross-sectional studies apply. Severity of the illness could not be assessed though the use of relevant medical procedures was taken into account. Quality of healthcare is an important dimension but it could not be addressed. There is a possibility that the sample included a few cases of more than one hospitalisation from the same family.

\section{Abbreviations}

CHE: Catastrophic health expenditure; CHE40: Catastrophic health expenditure at threshold of $40 \%$ of non-food expenditure; INR: Indian Rupees; OOPE: Out-of-pocket expenditure; PFHI: Publicly Funded Health Insurance; PMJAY: Pradhan Mantri Jan Arogaya Yojana; USA: United States of America.

\section{Supplementary Information}

The online version contains supplementary material available at https://doi. org/10.1186/s13104-022-05977-6.

Additional file 1: Table S1. List of study variables. List of variables used in the study.

Additional file 2: Table S2. Linear regression for determinants of OOPE on COVID-19 hospitalisation. Results of linear regression for determinants of Out of Pocket Expenditure (OOPE) on COVID-19 hospitalisation.

\section{Acknowledgements}

Not applicable.

\section{Authors' contributions}

SG, KB and NT contributed to the study design; SG, KC and NT contributed to writing of the manuscript. SG, KB, NT and KC analyzed the data; KB, NT and SG contributed to design of tools and KB, NT, KC and SG contributed to the datacollection. All authors read and approved the final manuscript.

\section{Funding}

No funding was obtained for this study.

\section{Availability of data and materials}

The datasets used and/or analysed during the current study available from the corresponding author on reasonable request.

\section{Declarations}

Ethics approval and consent to participate

The ethics approval for the study was obtained from the Institutional Ethics Committee of the State Health Resource Centre, Chhattisgarh [Reference number: SHRC-04-2020]. Because of the pandemic, a phone based survey was approved. The ethics approval included the detailed protocol for obtaining and documenting the informed consent of participants for the telephonic interviews. The consent form was read out to each participant. The interview was started only when an explicit consent was provided by each participant. A log was maintained for every call —name of caller, date and time, note that the prescribed text was used for asking consent, record of participant's response and signature of caller. In order to ensure confidentiality, an in-house call-centre was used. The callers were trained rigorously in the protocol for asking informed consent and documenting it. The calls were supervised closely to ensure adherence to the protocol. The log of each caller was examined and signed daily by the concerned supervisor. The dataset was completely anonymised.

\section{Consent for publication}

Not applicable. 


\section{Competing interests}

The authors declare that there are no competing interests.

Received: 9 November 2021 Accepted: 16 February 2022 Published online: 03 March 2022

\section{References}

1. Paremoer L, Nandi S, Serag H, Baum F. COVID-19 pandemic and the social determinants of health. BMJ. 2021;372: n129. https://doi.org/10.1136/ bmj.n129.

2. Shadmi E, Chen Y, Dourado I, Faran-Perach I, Furler J, Hangoma P, et al. Health equity and COVID-19: global perspectives. Int J Equity Health. 2020;19:104

3. Ataguba JE. COVID-19 pandemic, a war to be won: understanding its economic implications for Africa. Appl Health Econ Health Policy. 2020;2020(18):325-8. https://doi.org/10.1007/s40258-020-00580-x.

4. University of Minnesota. COVID-19 hospitalization tracking project. https://carlsonschool.umn.edu/mili-misrc-COVID19-tracking-project. Accessed 16 Sept 2021.

5. Prinja S, Pandav CS. Economics of COVID-19: challenges and the way forward for health policy during and after the pandemic. Indian J Public Health. 2020:64:S231-3.

6. Parashar R, Mukherjee A. The COVID-19 pandemic and associated catastrophic financial burden: a tragedy still in the making. 2020. https://blogs.Ishtm.ac.uk/hppdebated/2020/12/09/the-COVID-19pandemic-and-associated-catastrophic-financial-burden-a-trage dy-still-in-the-making/.

7. El-Khatib Z, Out A, Neogi U, Yaya S. The association between out-ofpocket expenditure and COVID-19 mortality globally. J Epidemiol Glob Health. 2020;10(3):192-3. https://doi.org/10.2991/jegh.k.200725.001.

8. Iyanda AE, Adeleke R, Lu Y, Osayomi T, Adaralegbe A, Lasode M, ChimaAdaralegbe NJ, Osundina AM. A retrospective cross-national examination of COVID-19 outbreak in 175 countries: a multiscale geographically weighted regression analysis (January 11-June 28). J Infect Public Health. 2020;13(10):1438-45. https://doi.org/10.1016/j.jiph.2020.07.006.

9. Patel V, Parikh R, Nandraj S, Balasubramaniam P, Narayan K, Paul VK, et al. Assuring health coverage for all in India. Lancet. 2015;386:2422-35.

10. National Health Systems Resource Centre. National Health Accounts Estimates for India FY 2016-17. October 2019. National Health Accounts Technical Secretariat (NHATS), National Health Systems Resource Centre (NHSRC), Ministry of Health and Family Welfare (MoHFW). Government of India. New Delhi. http://nhsrcindia.org/sites/default/files/FINAL\%20Nat ional\%20Health\%20Accounts\%202016-17\%20Nov\%202019-for\%20Web. pdf. Accessed 15 Jan 2021.

11. Parliament of India. The outbreak of pandemic COVID-19 and its management. Parliamentary Standing Committee on Health and Family Welfare. Report No. 123. November, 2020. New Delhi.

12. Government of India. Testing and treatment for COVID-19 under Ayushman Bharat Pradhan Mantri Jan Arogaya Yojana. Office Memorandum. National Health Authority. 2020.

13. Government of Chhattisgarh. Price caps for treatment of COVID-19 cases in private hospitals. 2020.

14. Government of Madhya Pradesh. Treatment of COVID-19 cases in private hospitals. 2020

15. Government of Delhi. Rates for treatment of COVID-19 cases in private hospitals. 2020

16. Government of Andhra Pradesh. Inclusion of certain procedures under Dr YSR Aarogyasri scheme to treat the cases of suspected and confirmed positive COVID-19 cases. 2020

17. Government of Telangana. COVID-19: fixation of ceiling of rates chargeable by private hospitals and laboratories for treatment and testing. 2020

18. Government of Kerala. Fixing of rates for treatment of COVID-19 cases in private healthcare institutions. 2020

19. Government of Tamil Nadu. Tamil Nadu health systems project—COVID19: inclusion of new packages for treatment and testing of COVID-19 for beneficiaries under CMCHIS/General Public in empanelled private hospitals and labs - payment to private hospitals - fixation of ceiling rates. 2020 .
20. Garg S, Bebarta KK, Tripathi N. Performance of India's national publicly funded health insurance scheme, Pradhan Mantri Jan Arogaya Yojana (PMJAY), in improving access and financial protection for hospital care: findings from household surveys in Chhattisgarh state. BMC Public Health. 2020;20:949.

21. Government of Chhattisgarh. Guidelines for treatment of COVID-19 cases in private hospitals. Department of Health and Family Welfare. 2020. http://cghealth.nic.in/ehealth/COVID19/pages/index.html. Accessed 23 Mar 2021.

22. Government of Chhattisgarh. Guidelines for home isolation of COVID-19 cases. Department of Health and Family Welfare. 2020. http://cghealth. nic.in/ehealth/COVID19/pages/index.html. Accessed 23 Mar 2021.

23. State Health Agency. Dr. Khubchand Baghel Sawsthya Sahayta Yojana. State Health Agency. Government of Chhattisgarh. https://dkbssy.cg.nic. in/about-us.aspx. Accessed 23 Mar 2021.

24. National Health Authority. PMJAY implementation fact sheet-Chhattisgarh. Ayushman Bharat_-Pradhan Mantri Jan Arogaya Yojana. National Health authority. 2021. https://pmjay.gov.in/states/status-implementa tion. Accessed 23 Mar 2021

25. State Nodal Agency. Package of rates for treatment of COVID-19 in empanelled private hospitals. Government of Chhattisgarh. 2020.

26. United Nations. Carrying out a telephone survey under the impact of COVID-19-What to consider. Department of Economic and Social Affairs. 2020. https://COVID-19-response.unstatshub.org/statistical-progr ammes/telephone-surveys-what-to-consider/.

27 Dabalen A, Etang A, Hoogeveen J, Mushi E, Schipper Y, von Engelhardt J. Mobile phone panel surveys in developing countries: a practical guide for microdata collection. Directions in development. Washington, DC: World Bank; 2016. https://doi.org/10.1596/978-1-4648-0904-0.

28. Samuels F. Tips for collecting primary data in a COVID-19-era-toolkit. ODI. 2020. https://odi.org/en/publications/tips-for-collecting-prima ry-data-in-a-COVID-19-era/.

29. Hinson L, Schaub E, Aya N, Tamboura-Diawara A, Trasi R. Pivoting in the face of the unknown: five adaptations for effective phone-based data collection during COVID-19. Pathfinder International. 2020. https://www. pathfinder.org/five-adaptations-for-data-collection/.

30. Wagstaff A, Doorslaer E. Catastrophe and impoverishment in paying for healthcare: with applications to Vietnam 1993-98. Health Econ. 2003;12:921-34.

31. Anindya $\mathrm{K}, \mathrm{Ng} \mathrm{N}$, Atun $\mathrm{R}$, et al. Effect of multimorbidity on utilisation and out-of-pocket expenditure in Indonesia: quantile regression analysis. BMC Health Serv Res. 2021;21:427. https://doi.org/10.1186/ s12913-021-06446-9.

32. Garg S, Tripathi N, Ranjan A, Bebarta KK, et al. Comparing the average cost of outpatient care of public and for-profit private providers in India. BMC Health Serv Res. 2021;21:838. https://doi.org/10.1186/ s12913-021-06777-7.

33. Ritchie H, Mathieu E, Rodés-Guirao L, Appel C, Giattino C, Ortiz-Ospina E, et al. Daily new confirmed COVID-19 cases. Coronavirus pandemic (COVID-19). https://ourworldindata.org/coronavirus/country/india.

34 Thiagarajan K. COVID-19 exposes the high cost of India's reliance on private healthcare. BMJ. 2020. https://doi.org/10.1136/bmj.m3506.

35. Nair, S. COVID-19 treatment: from affordable public hospitals to expensive private care, what it costs to treat a patient in India. 2020. https:// www.firstpost.com/health/. Accessed 2 Dec 2020.

36. Duggal R, Hooda SK. COVID-19, health insurance and access to healthcare. Econ Polit Wkly. 2021;53(31):10-2.

37. Ranjan A, Dixit P, Mukhopadhyay I, Sundararaman T. Effectiveness of government strategies for financial protection against costs of hospitalization care in India. BMC Public Health. 2018;18(1):501. https://doi.org/10.1186/ s12889-018-5431-8

38. Garg S, Chowdhury S, Sundararaman T. Utilisation and financial protection for hospital care under publicly funded health insurance in three states in Southern India. BMC Health Serv Res. 2019;19:1004.

39. Nandi S, Schneider H, Dixit P. Hospital utilisation and out of pocket expenditure in public and private sectors under the universal government health insurance scheme in Chhattisgarh state, India: lessons for universal health coverage. PLOS ONE. 2017;12(11): e0187904. https://doi. org/10.1371/journal.pone.0187904.

40. Bhat R. Characteristics of Private medical practice in India: a provider perspective. Health Policy Plan. 1999;14(1):26-37. 
41. Nandi S, Schneider H. When state-funded health insurance schemes fail to provide financial protection: an in-depth exploration of the experiences of patients from urban slums of Chhattisgarh, India. Glob Public Health. 2019. https://doi.org/10.1080/17441692.2019.1651369.

42. Sheikh K, Prasanna SS, Hort K. What explains regulatory failure? Analysing the architecture of health care regulation in two Indian states. Health Policy Plan. 2015;30(1):39-55.

43. Mackintosh M, Channon A, Karan A, Selvaraj S, Zhao H, Cavagnero E, et al. What is the private sector? Understanding private provision in the health systems of low-income and middle-income. Lancet. 2016;6736(16):1-10.

44. Hernández-Vásquez A, Rojas-Roque C, Barrenechea-Pulache A, BendezuQuispe G. Measuring the protective effect of health insurance coverage on out-of-pocket expenditures during the COVID-19 pandemic in the Peruvian population. Int J Health Policy Manag. 2021. https://doi.org/10. 34172/ijhpm.2021.154.

45. Chua K, Conti RM, Becker NV. Assessment of out-of-pocket spending for COVID-19 hospitalizations in the US in 2020. JAMA Netw Open. 2021;4(10): e2129894. https://doi.org/10.1001/jamanetworkopen.2021. 29894.

46. Tsai Y, Vogt TM, Zhou F. Patient characteristics and costs associated with COVID-19-related medical care among medicare fee-for-service beneficiaries. Ann Intern Med. 2021;174(8):1101-9. https://doi.org/10.7326/ M21-1102 (Epub 2021 Jun 1).

47. Hellowell M, Okafor Y. Understanding the impact of COVID-19 on the private health sector in Africa. Posted on March 9, 2021 by BMJ GH Blogs.

48. Sanders D, Nandi S, Labonte R, Vance C, Damme WV. From primary health care to universal health coverage-one step forward and two steps back. Lancet. 2019;394(10199):619-21. https://doi.org/10.1016/S0140-6736(19) 31831-8.

49. Olalere N. Pause and reflect, July reflections, SPARC. 2020. https://sparc. africa/2020/08/july-reflections/. Accessed 5 Mar 2021.

50. Tsilaajav T, Mathauer I, de Oliveira Cruz V. Purchasing health services to respond to COVID-10: how to involve and contract private sector providers in the South-East Asia Region? 2020. https://p4h.world/en/who-purch asing-health-services-to-respond-to-COVID-19-how-to-involve-and-contr actprivate-sector-providers-in-south-east-asia-region. Accessed $5 \mathrm{Mar}$ 2021.

51. Mathauer I, Dkhimi F, Townsend M. Adjustments in health purchasing as part of the COVID-19 health response: results of a short survey and lessons for the future. Geneva: Department of Health Systems Governance and Financing, World Health Organization; 2020.

52. NITI Ayog. Health system for a New India: building blocks—-potential pathways to reform. New Delhi: NITI Aayog (National Institute for Transforming India); 2019.

53 Sarwal R, Prasad U, Madangopal K, Kalal S, Kaur D, Kumar A, Regy P, Sharma J. Investment opportunities in India's healthcare sector. New Delhi: NITI Aayog; 2021

54. Zakoji M, Sundararaman T. Emerging good practices and lessons learnt to maintain essential health services during the COVID-19 pandemic. WHO South-East Asia J Public Health. 2021;10(Suppl S1):26-9.

\section{Publisher's Note}

Springer Nature remains neutral with regard to jurisdictional claims in published maps and institutional affiliations.

Ready to submit your research? Choose BMC and benefit from:

- fast, convenient online submission

- thorough peer review by experienced researchers in your field

- rapid publication on acceptance

- support for research data, including large and complex data types

- gold Open Access which fosters wider collaboration and increased citations

- maximum visibility for your research: over $100 \mathrm{M}$ website views per year

At BMC, research is always in progress.

Learn more biomedcentral.com/submissions 